\title{
PEMETAAN TINGKAT KENYAMANAN JALUR SEPEDA DAERAH MALIOBORO DENGAN MENGGUNAKAN DATA PENGINDERAAN JAUH
}

\author{
(Comfort Level Of Bicycle Lane Mapping In Malioboro Using Remote Sensing Data) \\ Wenang Anurogo', Wikan Jaya Prihantarto ${ }^{2}$, Isti Fadhatul $\mathrm{K}^{3}$, Asih Dewi Nugraheni ${ }^{4}$, Dana Krisna \\ Prabawa $^{5}$, Tatag Waruju Wikan P6, Dwi Gegana ${ }^{7}$, Yanuar Adji Nugroho7 ${ }^{7}$, Satrio Hanindhito ${ }^{8}$ \\ Catur Agus Lukitasari ${ }^{9}$, Novita Ayu Dewanti ${ }^{10}$ \\ Lecturer Department of Informatics Engineering, Geomatics Engineering Batam State Polytechnic ${ }^{1}$ \\ Master Student Remote Sensing Departement Gadjah Mada University ${ }^{2}$ \\ Master Student Pshycological Departement Gadjah Mada University ${ }^{3}$ \\ Expert Staff National Board for Disaster Management ${ }^{4}$ \\ Owner Systemaptic Consultant ${ }^{5}$ \\ Research Staff CV. Karya Hidup Sentosa - QUICK Traktor ${ }^{6}$ \\ GIS Staff PT Freeport Indonesia ${ }^{7}$ \\ Owner Catchlight Pictures Indonesia 8 \\ Master Student Physical Education Departement Ahmad Dahlan University ${ }^{9}$ \\ Bachelor Student Mathematic Education Departement Surakarta State University ${ }^{10}$ \\ Batam Center,Kota Batam Provinsi Kepulauan Riau, 29461 Indonesia \\ E-mail: wenang@polibatam.ac.id
}

\begin{abstract}
ABSTRAK
Sepeda merupakan alat transportasi yang ramah lingkungan. Dewasa ini banyak kota besar yang memfasilitasi pengguna sepeda dengan adanya jalus khusus sepeda. Yogyakarta merupakan tempat akulturasi budaya. Salah satu budaya yang disajikan adalah budaya jalan kaki dan bersepeda bagi masyarakat. Lokasi tempat bersepeda dikawasan Yogyakarta yang terkenal salah satunya berada dikawasan malioboro. Selain sebagai kawasan Central Bussines Distric (CBD) atau kawasan pusat bisinis di Yogyakarta, kawasan malioboro juga merupakan kawasan ikon bagi para pelancong untuk menikmati suasana di kota pelajar tersebut. Penelitian ini bertujuan untuk mengetahui tingkat kenyamanan jalur sepeda dikawasan malioboro dan menyajikannya kedalam suatu data spasial sehingga dapat mudah dipahami. Tingkat kenyamanan pengendara sepeda dapat di ekstraksi dari data penginderaan jauh dan data survei lapangan. Tingkat kenyamanan tersebut di ekstrak menjadi parameter yang mempengaruhi tingkat kenyamanan pengendara sepeda khususnya di kawasan malioboro Yogyakarta. Parameter yang digunakan pada penelitian ini hasil dari ekstraksi data penginderaan jauh resolusi tinggi adalah parameter vegetasi peneduh, hambatan samping, marka jalur sepeda, posisi jalur, kepadatan lalulintas, dan relief. Hasil penelitian menunjukkan bahwa dikawasan malioboro terdapat 8 jalur sepeda sangat nyaman, 16 jalur sepeda dengan kelas nyaman, 7 jalur dengan kelas sedang, 38 jalur sepeda dengan kelas tidak nyaman dan 20 jalur sepeda dengan kelas sangat tidak nyaman.
\end{abstract}

Kata kunci: Jalur Sepeda, Sepeda, Tingkat Kenyamanan Jalur Sepeda, Penginderaan Jauh, Data Spasial

\begin{abstract}
Bicycles are an environmentally friendly device of transportation. Today many big cities are facilitating bicycle users with a special bicycle lane. Yogyakarta is a place of cultural acculturation. One of the cultures presented is the culture of walking and cycling for the society. One of the fomous location of cycling place in Yogyakarta is in malioboro area. Aside from being the Central Bussines Distric (CBD) of Yogyakarta, malioboro area is also an iconic area for travelers to enjoy the atmosphere in it. This research aims to determine Comfort Level Of Bicycle Lane in malioboro and and presents it into a spatial data that can be easily understood. The comfort level of cyclists can be extracted from remote sensing data and field survey data. The level of comfort is extracted into parameters that affect the comfort level of cyclists especially in the area malioboro Yogyakarta. The parameters used in this study, resulted from high resolution remote sensing data extraction are shade vegetation, side obstacles, bike lane mark, path position, traffic density, and relief. The results show that there are 8 bike paths with very comfortable class, 16 bicycle lanes with comfortable class, 7 lines with medium grade, 38 bike lines with uncomfortable class and 20 bike lanes with very uncomfortable class.
\end{abstract}

Keywords: Bicycle Path, Bicycle, Comfort Level Of Bicycle Lane, Remote Sensing, Spasial Data 


\section{PENDAHULUAN}

Yogyakarta sebagai kota pelajar dan daerah yang berbudaya terkenal dengan keramahan akan masyarakat lokalnya. Berbagai macam kebudayaan berkumpul dan melebur beralkulturasi menjadi satu di kota tersebut. Salah satu jenis akulturasi budaya yang disajikan di Yogyakarta adalah budaya jalan kaki dan bersepeda bagi masyarakat. Tersedianya kawasan pedestrian dan jalur sepeda di hampir semua sudut jalan memudahkan pengguna sepeda dan pejalan kaki untuk menggunakannya.

Lokasi tempat bersepeda dikawasan Yogyakarta yang terkenal salah satunya berada dikawasan malioboro. Selain sebagai kawasan Central Bussines Distric (CBD) atau kawasan pusat di Yogyakarta, kawasan malioboro juga merupakan kawasan ikon bagi para pelancong untuk menikmati suasana di kota pelajar tersebut (Anurogo et al 2017).

Data penginderaan jauh sudah digunakan sebagai alat bantu untuk mengeksplorasi lahan yang ada di indonesia sejak awal tahun 1960 (danoedoro, 2012). Kemampuan ekstraksi data penginderaan jauh resolusi tinggi dapat digunakan sebagai alat bantu identifikasi segala macam jenis objek yang terekam di permukaan bumi. Dilihat dari pengertiannya bahwa penginderaan jauh merupakan suatu proses pengukuran atau perolehan informasi berupa data sebaran fenomena atau sifat obyek tertentu, dilakukan menggunakan alat perekaman tanpa kontak langsung dengan obyek yang dikaji (Anurogo et al 2017; Sari dan Lubis, 2017), sehingga pemanfaatan data penginderaan jauh dapat mempermudah dalam melakukan kajian dengan area yang lebih luas jika dibandingkan dengan pengukuran terestrial (Kiefer, T. M., \& Lillesand, R. W. 1990).

\section{METODE}

Metode penelitian adalah tahapan yang dilakukan untuk menyelesaikan tujuan dari penelitian ini termasuk didalamnya pengumpulan data, pengolahan data, sampai dengan analisis data (Anurogo, 2015). Metode penelitian yang digunakan dalam penelitian ini adalah ekstraksi data penginderaan jauh resolusi tinggi (quickbird) untuk mendapatkan parameter - parameter tingkat kenyamanan jalur sepeda dengan menggunakan cara interpretasi visual. Data parameter hasil ekstraksi tersebut kemudian divalidasi dengan data lapangan dan dianalisis untuk menghasilkan data spasial (Lubis et al 2017) tetang kenyamanan jalur sepeda dikawasn malioboro.

Lokasi penelitian ini terletak di kawasan Central Bussines District (CBD) Malioboro. Kawasan ini terletak di antara koordinat $X$ : 429400 Y:9138800 dan X: 430600 Y: 9137600 koordinat UTM datum WGS 84 zona 49S. Lokasi penelitian di tunjukkan pada gambar 1.

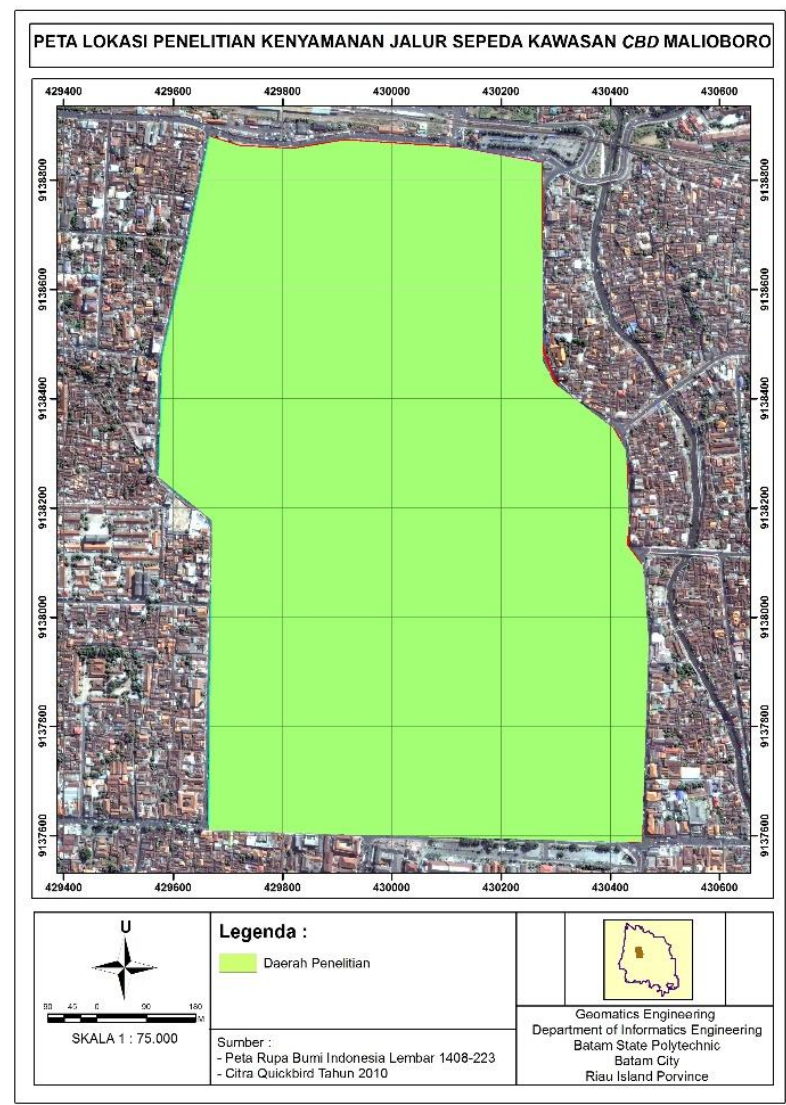

Gambar 1. Lokasi penelitian kawasan $C B D$ Malioboro 
Data parameter didapatkan dari interpretasi citra penginderaan jauh resolusi tinggi. Interpretasi menurut pengertiannya adalah cara mengambil informasi atau mengidentifikasi objek dan menilai arti penting objek tersebut.

Dalam melakukan interpretasi secara manual atau visual, dapat menggunakan kunci interpretasi sebagai berikut (Jensen, 2009):

- Tekstur: merupakan perubahan rona pada citra. Tekstur biasanya dinyatakan kasar, sedang, dan halus.

- Bentuk: adalah gambar yang mudah dikenali,

- Rona: menunjukkan perbedaan gelap terangnya suatu objek.

- Warna, pada daun dapat dipakai untuk mengenali jenis vegetasi. Vegetasi daerah tropis selalu hijau, sedangkan vegetasi di daerah sub tropis pada musim gugur tidak berdaun. Pada warna asli vegetasi yang semakin hijau warnanya menunjukkan vegetasinya semakin lebat.

- Ukuran: adalah ciri objek berupa jarak, luas, tinggi, dan volume. Ukuran objek pada citra bergantung pada skala.

- Pola: susunan keruangan yang menandai banyak bentukan objek secara alami maupun buatan manusia.

- Situs: merupakan letak suatu objek terhadap objek lain di sekitarnya.

- Bayangan mempunyai sifat menyembunyikan objek yang berada didaerah gelap, tetapi dengan adanya bayangan akan mempermudah dalam mengenali beberapa objek.

- Asosiasi: merupakan keterkaiatan antara objek yang satu dengan objek yang lain.

Penentuan jalur kenyamanan sepeda pada penelitian ini didapatkan dari penggabungan parameter - parameter yang dianggap berperan dalam mempengaruhi tingkat kenyamanan sepeda di kawasan malioboro. Parameter tersebut didapatkan dengan cara interpretasi data citra quickbird. Setelah didapatkan hasil dari interpretasi tersebut, parameter - parameter itu kemudian diberikan faktor pembobot pada masing - masing kelasnya. Faktor pembobot tersebut lah kemudian dijadikan dasar sebagai penentuan kelas kenyamanan jalur sepeda dengan ketentuan kelas yang mempunyai nilai rendah pada masing masing parameter merupakan kelas yang paling tidak berpengaruh. Kelas yang paling tidak berpengaruh tersebut merupakan jalur yang paling tidak nyaman karena nilai pengaruh pada masing - masing parameter kecil. Setelah mendapatkan skor total dari masing - masing parameter kenyamanan pada masing - masing ruas jalan, nilai skor tersebut kemudian dikalikan dengan factor pengali untuk mendominasikan parameter yang paling berpengaruh diantara parameter parameter lainnya. Parameter yang paling berpengaruh dikalikan dengan factor pengali yang lebih besar dibandingkan dengan parameter yang kurang berpengaruh lainnya, sehingga tidak terjadi bias terhadap parameter - parameter lainnya. Nilai skor total hasil kali dengan factor pengali tersebut kemudian di klasifikasikan menjadi 5 kelas tingkat kenyaman jalur pengendara sepeda mulai dari sangat nyaman sampai dengan sangat tidak nyaman (Farizki \& Anurogo, 2017). Parameter di tampilkan dalam tabel 1.

Parameter - Parameter tersebut kemudian setelah diberikan pembobotan harkat pada masing - masing, kemudian dilakukan analisis overlay atau tumpang susun dengan alat bantu Sistem Informasi Geografis (SIG) untuk mengetahui tingkat kenyamanan jalur sepeda. SIG adalah suatu sistem manual dan atau komputer yang digunakan untuk mengumpulkan, menyimpan, mengelola, dan menghasilkan informasi yang mempunyai rujukan spasial atau geografis (Danoedoro, 2012). Pemanfaatan Sistem Informasi Geografis memiliki berbagai keunggulan khususnya dalam proses penerimaan, pengolahan dan analisis data secara spasial dalam jumlah yang besar namun tetap efektif. Keunggulan pemrosesan secara spasial lainnya adalah dalam keutamaan menipulasi data spasial yang tersedia sehingga berbagai masukan data atau atribut berbeda dapat diintegrasikan untuk hasil analisis yang ingin dicapai. Berikut ini adalah proses penyusunan basis data untuk memperoleh informasi geografis dalam bentuk data spasial.

Survey lapangan dilakukan untuk mendapatkan informasi tambahan guna melengkapi data parameter maupun juga untuk mengambil informasi yang tidak bias diekstraksi secara langsung menggunakan data penginderaan jauh. Informasi tambahan yang didapatkan dalam survey lapangan ini untuk tambahan informasi mengenai parameter yang mempengaruhi tingkat kenyamanan jalur sepeda (HIDAYAT, F. N., \& Widartono, B. S. 2014) 
Tabel 1. Tabel parameter tingkat kenyamanan Jalur Sepeda

\begin{tabular}{|c|c|c|c|c|c|c|c|c|}
\hline No & $\begin{array}{c}\text { Tingkat } \\
\text { kenyamanan }\end{array}$ & $\begin{array}{l}\text { Arus } \\
\text { Lalu } \\
\text { Lintas }\end{array}$ & $\begin{array}{c}\text { Marka } \\
\text { Jalur } \\
\text { Sepeda }\end{array}$ & Relief & $\begin{array}{c}\text { Hambatan } \\
\text { Samping }\end{array}$ & $\begin{array}{l}\text { Posisi } \\
\text { Jalur }\end{array}$ & $\begin{array}{l}\text { Vegetasi } \\
\text { Peneduh }\end{array}$ & $\begin{array}{l}\text { Skor } \\
\text { Total }\end{array}$ \\
\hline 1 & $\begin{array}{l}\text { Sangat } \\
\text { Nyaman }\end{array}$ & & & & & & & \\
\hline 2 & Nyaman & & & & & & & \\
\hline 3 & Sedang & & & & & & & \\
\hline 4 & $\begin{array}{c}\text { Tidak } \\
\text { Nyaman }\end{array}$ & & & & & & & \\
\hline 5 & $\begin{array}{l}\text { Sangat } \\
\text { Tidak } \\
\text { Nyaman }\end{array}$ & & & & & & & \\
\hline
\end{tabular}

Sumber : analisis data 2014

\section{HASIL DAN PEMBAHASAN}

Penggunaan data penginderaan jauh dalam penelitian ini melalui beberapa tahapan. Tahapan pre processing, processing, dan analisis data hasil pemrosesan. Tahapan pertama yang dilakukan dalam penelitian ini adalah tahapan pre processing. Tahapan ini merupakan tahapan awal dalam penggunaan data penginderaan jauh. Tahapan awal yang dilakukan adalah tahapan penyesuaian posisi citra yang digunakan dengan posisi koordinat yang ada dilapangan, atau lebih sering dikenal dengan sebutan koreksi geometrik. Koreksi geometrik sistematik merupakan koreksi yang ditujukan untuk memperbaiki kesalahan yang telah diperhitungkan akibat rotasi bumi, sudut pandang sensor, kecepatan wahana, variasi kecepatan cermin, distorsi penyiaman, dan kemiringan garis penyiam. Koreksi geometrik sistematik ini akan memberikan efek perubahan bentuk scene citra dari bujur sangkar menjadi jajar genjang. Penelitian ini menggunakan citra Quickbird pada level 1B yang artinya data yang digunakan telah melalui tahap koreksi geometri sistematik tetapi walaupun sudah melalui tahap tersebut masih perlu dilakukan proses koreksi geometri non-sistematik.

Data setelah dilakukan proses koreksi geometrik, kemudian dilakukan proses penajaman citra. Penajaman citra (image enhacement) meliputi semua operasi yang menghasilkan citra baru dengan kenampakan visual dan karakteristik spektral yang berbeda. Penajaman citra bertujuan untuk peningkatan mutu citra, yaitu menguatkan kontras kenampakan yang tergambar dalam citra digital. Penajaman citra dilakukan sebelum penampilan citra atau sebelum dilakukan interpretasi, dengan maksud untuk menambah jumlah informasi yang dapat diinterpretasi secara digital. Proses penajaman dapat menghasilkan citra yang lebih kontras dan detail, namun adapula yang menghasilkan citra yang hanya memperjelas batas tepi dengan informasi yang kurang detail. Penajaman citra dapat dilakukan melalui tiga metode yaitu :

- Manipulasi kontras citra (contrast manipulation), teknik ini dapat dilakukan dengan gray- level thresholding, level slicing, dan contrast strecthing.

- Manipulasi kenampakan secara spasial (spatial feature manipulation), dapat dilakukan dengan spatial filtering, edge enhacement, dan fourier analysis.

Penajaman citra merupakan pengolahan data awal (pre-processing operations) yang bertujuan untuk mendapatkan nilai citra yang lebih sesuai dengan tujuan interpretasi. Penajaman citra dimaksudkan untuk memperjelas tampilan citra sehingga memudahkan dalam proses klasifikasi obyek penggunaan lahan. Penajaman yang dilakukan pada citra disesuaikan dengan informasi yang ingin disadap dari citra.

Penyusunan komposit warna bertujuan untuk mendapatkan gambaran visual yang lebih baik sehingga pengamatan obyek, pemilihan sampel dan aspek estetika citra dapat diperbaiki. Citra yang digunakan adalah Quickbird terdapat 4 saluran yaitu merah, hijau, biru dan inframerah dekat dan pankromatik. Komposit warna pada penelitian ini mendukung mendapatkan informasi pada tingkat kenyamanan jalur sepeda di kawasan CBD di Malioboro. Komposit warna yang digunakan pada penelitian ini adalah komposit 321 atau true color, digunakan karena memudahkan dalam proses identifikasi dan interpretasi.

Komposit true color merupakan komposit warna standar yang sama seperti persepsi visual yang dilihat oleh mata manusia. Channel biru menggunakan band 1 (band biru) sedangkan channel hijau menggunkana band 2 (band hijau). Band 4 (inframerah) tidak digunakan dalam pembuatan komposit ini sehingga channel merah 
diisi dengan band 3 (merah). Objek yang memiliki pantulan yang tinggi pada band biru dan rendah pada kedua band lain yang digunakan dalam komposit akan memiliki warna biru, sebagai contoh objek air pada kolam renang di sekitar lokasi penelitian. Hasil komposit warna dari citra quickbird ditampilkan pada gambar 2.

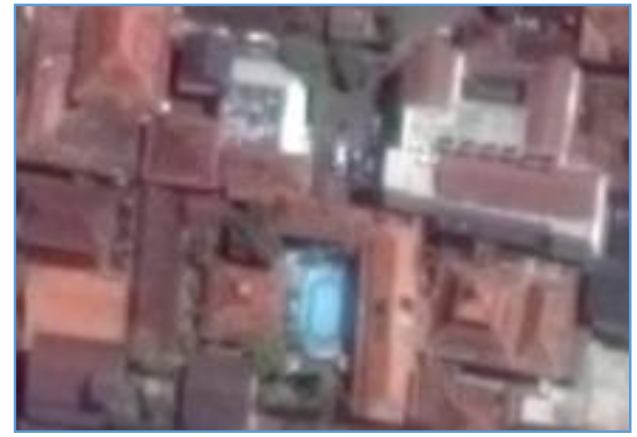

Gambar 2. Hasil Komposit Warna Citra Quickbird saluran 321

Data quickbird setelah melalui tahapan pra pemrosesan, baru bisa diolah dan diekstrak untuk menghasilkan parameter - parameter tingkat kenyamanan jalur sepeda dengan metode interpretasi visual.

Data pertama yang diekstraksi adalah informasi jaringan jalan diinterpretasi dengan membatasi batas kajian dan konseptual penelitian. Batas kajian dalam penelitian ini adalah jalan yang berada di sekitar Central Business Distric (CBD) Malioboro. Data jalan pada skala 1:25000 merupakan data acuan yang palin detail yang beredar. Sekalipun kajian berada pada skala pemetaan yang lebih besar, namum penggunaan data dasar $\mathrm{RBI}$ tersebut dinilai masih bisa dijadika acuan karena detail kelas jalan yang ada masih dapat mengakomodir kebutuhan penelitian.

Pembatasan konseptual dilakukan untuk menjadikan penelitian ini tepat secara metodologis. Asumsi yang digunakan peneliti adalah mendasarkan pada pemahaman dimana jaringan jalan yang dapat digunakan dalam aktifitas pedestrian dan jalur sepeda memiliki kelas jalan tertentu yang dapat mendukung. Sekalipun aktifitas pedestrian dapat dilakukan hingga kelas jalan setapak, namun kelas jalan setapak tidak disertakan pada analisis kenyamanan pesepeda.

Berdasarkan referensi, jalan kolektor primer adalah jalan yang dikembangkan untuk melayani dan menghubungkan kota-kota antar pusat kegiatan wilayah dan pusat kegiatan lokal dan atau kawasan-kawasan berskala kecil. Kelas jalan ini memiliki fungsi sebagai penghubung/terusan jalan kolektor primer luar kota atau menghubungkan jalan arteri. Jalan kolektor primer dirancang untuk menampung lalu lintas dengan kecepatan minimal $40 \mathrm{~km} / \mathrm{jam}$. Sedangkan lebar jalan yang diizinkan adalah 7 meter dengan jumlah jalan masuk ke jalan kolektor primer dibatasi secara efisien. Jarak antar jalan masuk/akses langsung tidak boleh lebih pendek dari 400 meter. Adapun peta kelas jalan daerah penelitian ditampilkan dalam gambar 3 .

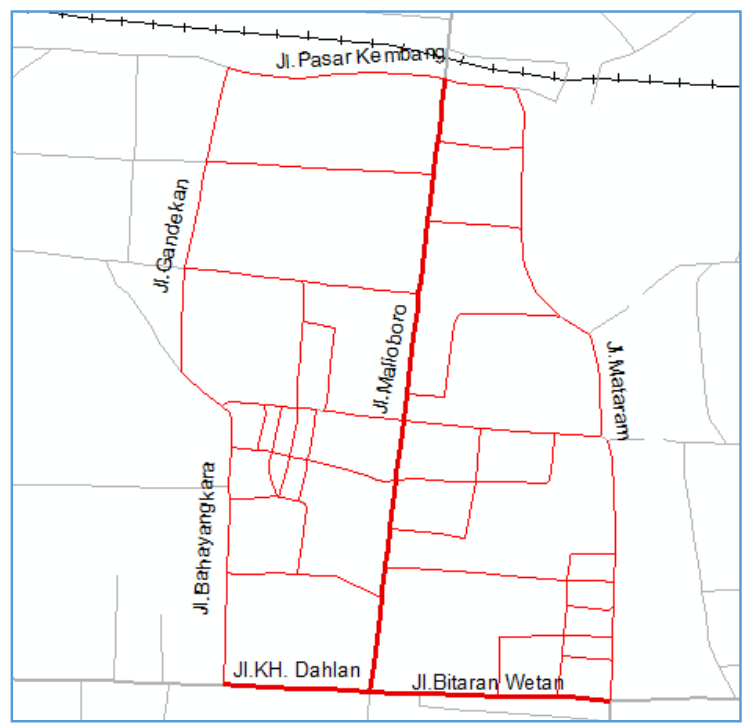

Gambar 3. Peta kelas jalan kawasan malioboro

Berdasarkan peraturan lalu lintas yang ada kendaraan angkutan barang berat dan bus dapat diizinkan melalui jalan ini sedangkan persimpangan pada jalan kolektor primer diatur dengan pengaturan tertentu yang sesuai dengan volume lalu lintasnya. Jalan kolektor primer mempunyai kapasitas yang sama atau lebih besar dari volume lalu lintas rata-rata. Karena fungsinya yang cukup besar di lingkungan perkotaan, lokasi parkir pada badan jalan sangat dibatasi dan seharusnya tidak diizinkan pada jam sibuk. Jalan kelas koletor harus mempunyai perlengkapan jalan yang cukup seperti rambu lalu lintas, marka jalan, lampu lalu lintas dan lampu penerangan jalan. Pada kelas jalan ini juga dianjurkan tersedianya jalur khusus yang dapat digunakan untuk sepeda dan kendaraan lambat lainnya.

Jalan lokal primer adalah jalan yang menghubungkan secara berdaya guna pusat kegiatan nasional dengan pusat kegiatan lingkungan, pusat kegiatan wilayah dengan pusat kegiatan lingkungan, antarpusat kegiatan lokal, atau pusat kegiatan lokal dengan pusat kegiatan lingkungan, serta antarpusat kegiatan lingkungan.

Jalan lokal adalah kelas jalan lain yang ada pada daerah penelitian. Jalan lokal memiliki fungsi sebagai terusan dari jalan lokal primer dan jalan kolektor dari luar kota. Jalan lokal juga dapat menghubungkan kawasan primer dengan jalan primer. Jalan ini mampu menampung lalu lintas dengan batas bawah kecepatan $20 \mathrm{~km} / \mathrm{jam}$. Kendaraan angkut barang dan bus juga diizinkan untuk melewati jalan ini. Lebar jalan yang dimungkinkan setidaknya 6 meter. Jalan lokal mendominasi jalan yang ada dalam daerah penelitian dimana setidaknya $80 \%$ jalan yang ada 
merupakan jalan dalam kelas jalan lokal. Contoh jalan lokal yang ada pada daerah kajian adalah Jalan Dagen. Hasil pengamatan lapangan menunjukkan kebanyakan jalan lokal yang ada memiliki satu lajur searah.

Peta kelas jalan yang diturunkan dari peta RBI selanjutnya digunakan sebagai dasar analisis pada tahapan berikutnya. Sebagai salah satu prosedur dasar, peneliti melakukan pengecekan hasil pemetaan untuk mendaptkan kondisi asli dari lapangan. Berdasarkan pengamatan lapangan, tidak semua ruas jalan memiliki kemampuan jalan untuk mendukung saranan pedetrian danaktifitas bersepeda meskipun, hampir keseluran kelas jalan sesuai. Sebagai contoh jalan protokol besar dengan arah barat-timur yang menjadi penghubung Jalan Malioboro dengan Jalan Mataram dan berada pada wilayah kompleks perkantoran Bupati DIY. Jalan tersebut memiliki kelas yang sesuai, namun tidak dapat digunakan karena akses ditutup oleh pembatasan pemanfaatan. Jalan tersebut tidak menjadi jalan umum karena digunakan sebagai jalan akses utama perkantoran tersebut.

Data kelas jalan hasil interpretasi tersebut kemudian digunakan sebagai dasar untuk penentuan jalur sepeda dikombinasikan dengan data yang diambil pada saat lapangan. Parameter tingkat kenyamanan jalur sepeda adalah data selanjutnya yang di kestraksi. Parameter yang dapat di ekstraksi langsung dengan menggunakan data penginderaan jauh ada enam parameter yaitu pengaruh kepadatan lalulintas, keberadaan marka penanda, hambatan samping, vegetasi peneduh, posisi jalur sepeda, analisis relief. Parameter parameter tersebut kemudian dikombinasikan dengan data lapangan untuk validasi hasil interpretasi.

Kepadatan lalulintas merupakan salah satu parameter dalam penentuan kenyamanan jalur sepeda. Kawasan Malioboro sebagai suatu kawasan Central Business Distrct (CBD) tentu merupakan kawasan yang tidak pernah sepi dari aktivitas baik yang berada di tempat pertokoan maupun di jalan raya. Kendaraan yang melintas bervariasi mulai dari kendaraan bermotor hingga yang tidak bermesin seperti sepeda, becak, dan andong. Pada penelitian ini jalur yang di lalui adalah jalur di sepanjang kawasan malioboro. Ruas jalan yang di lalui ada tujuh belas ruas jalan. Nama ruas jalan yang dilalui adalah jalan malioboro, jalan mataram, jalan Myor Sutomo, Jalan Gandekan, jalan Bhayangkara, jalan Pasar kembang, Jalan Sosoro Wijayan, jalan Dagen, jalan Pajeksan, jalan Besakalan, Jalan reksobayan, Jalan Ketandan, Jalan Suryatmajan, jalan Ketandan Wetan, jalan Sriwedani, dan Jalan Bintaran kulon. Kepadatan lalulintas pada masing masing ruas jalan bervariasi, namun cenderung padat. Dari tujuh belas ruas jalan tersebut hanya jalan reksobayan yang mendapat skor atau nilai 3 yang berarti tidak padat. Kepadatan lalulintas pada ruas jalan malioboro untuk jalur sepeda buruk karena banyaknya becak dan andong yang memakai jalur sepeda untuk beraktivitas. Pada ruas jalan lain seperti jalan pajeksan dan dagen didominasi lalulintas mobil yang akan menuju tempat penginapan maupun tempat usaha yang memang banyak tersedia di sepanjang ruas jalan tersebut, selain itu faktor menyempitnya ruas jalan akibat kendaraan roda empat yang parkir di pinggir jalan membuat lalulintas semakin tersendat.

Kelancaran arus lalu lintas dapat dipengaruhi oleh hambatan samping. Hambatan samping merupakan aktifitas penggunaan sisi jalan yang berdampak pada kinerja lalu lintas jalan. Hambatan tersebut dapat berupa pemberhentian angkutan kota, pejalan kaki yang tidak memanfaatkan trotoar tapi sisi jalan, serta kendaran yang memperlambat untuk keluar atau masuk ke sisi jalan. Kapasitas jalan akan semakin berkurang ketika hambatan samping meningkat. Terutama jalur sepeda yang memang ditempatkan pada sisi luar dari badan jalan akan terpengaruh tingkat kenyamanannya saat hambatan samping mendominasi badan jalan. Lokasi yang strategis dan pusat wisata berdampak pada tingkat keramaian jalur lalu lintas. Bus wisata memang tidak diperkenankan melewati sepanjang jalan malioboro kecuali bus kota dengan kapasitas kecil. Trotoar di sepanjang jalan Maliboro telah beralih fungsi menjadi lahan parkir baik sepeda motor, mobil, becak, andong, hingga menjadi tempat menjajakan dagangan. Kondisi tersebut berdampak pada beralihnya pejalan kaki ke sisi badan jalan. Alih fungsi trotoar yang terjadi selain mempengaruhi kenyamanan pejalan kaki sekaligus bagi pengguna sepeda. Karena kapasitas badan jalan yang berkurang secara langsung mengurangi ruang bagi pengguna sepeda.

Bedasarkan interpretasi daerah kajian terbagi menjadi dua kelas jalan. Jalan Kolektor primer meliputi Jalan Malioboro, Ahmad Yani, Bintaran Kulon dan Ahmad Dahlan dengan panjang total 2,069932 km. Sedangkan jalan dengan kelas lokal tersebar di sekitar lokasi dengan total panjang $10,143659 \mathrm{~km}$ yang terdiri dari 24 ruas. Kelas jalan pada daerah penelitian lebih jelasnya ditampilkan pada tabel 2. 
Pemetaan Tingkat Kenyamanan Jalur Sepeda Daerah Malioboro Dengan Menggunakan Data Penginderaan Jauh.

Tabel 2. Tabel kelas dan panjang jalan pada daerah penelitian

\begin{tabular}{|c|c|c|}
\hline Nama Jalan & Kelas Jalan & Panjang (Km) \\
\hline Abu Bakar Ali & Lokal & 0,239741 \\
\hline Ahmad Dahlan & Kolektor & 0,300462 \\
\hline Beskalan & Lokal & 0,374836 \\
\hline Bhayangkara & Lokal & 0,190767 \\
\hline Bintaran Kulon & Kolektor & 0,496924 \\
\hline Dagen & Lokal & 0,46053 \\
\hline Gadean & Lokal & 0,176439 \\
\hline Gandekan & Lokal & 0,193869 \\
\hline Ketandan & Lokal & 0,215536 \\
\hline Ketandan Wetan & Lokal & 0,193899 \\
\hline Malioboro & Kolektor & 1,272546 \\
\hline Mataram & Lokal & 0,146002 \\
\hline Mayor Suryotomo & Lokal & 0,184697 \\
\hline Mojar & Lokal & 0,190767 \\
\hline Pabringan & Lokal & 0,207033 \\
\hline Pajeksan & Lokal & 0,223536 \\
\hline Pasar Kembang & Lokal & 0,199289 \\
\hline Perwakilan & Lokal & 0,215536 \\
\hline Reksobayan & Lokal & 0,46053 \\
\hline Remujung & Lokal & 0,300462 \\
\hline Sosrowijayan & Lokal & 0,468257 \\
\hline Sriwedari & Lokal & 0,252923 \\
\hline Suryatmajan & Lokal & 0,24898 \\
\hline \multirow[t]{2}{*}{ Tilarso } & Lokal & 0,2332 \\
\hline & Total & 12,213592 \\
\hline
\end{tabular}

Sumber: Analisis Data 2015

Hasil lapangan menunjukkan beberapa ruas jalan di lokasi penelitian mempunyai variasi hambatan jalan dari rendah hingga tinggi. Dilakukan skoring untuk mengkoding dan digunakan sebagai data masukan pada proses pemodelan jalur sepeda. Jalur jalan yang mempunyai hambatan rendah yaitu di Jalan Reksobayan, dan Jalan Bintaran Kulon. Jalan Malioboro, Jalan Mataram, Jalan Dagen, Jalan Pajeksan, Jalan Beskalan, dan Jalan Pasar Kembang mempunyai hambatan samping tinggi Faktor hambatan samping tersebut merupakan salah satu penentu tingkat kenyamanan jalur sepeda yang diberi faktor pengali 4. Hambatan samping yang diberi kategori tinggi ekuivalen dengan tingkat gangguan pada jalur sepeda. Badan jalan yang seharusnya digunakan oleh pengguna sepeda semakin menyempit karena digunakan oleh pejalan kaki, terutama di sepanjang Jalan Malioboro, Jalan Mataram, Jalan
Dagen, dan Jalan Pasar Kembang. Trotoar yang ditujukan sebagai ruang pejalan kaki telah beralih fungsi menjadi tempat parkir dan menjajakan dagangan, sehingga pejalan kaki menggunakan sisi jalan dan mempersempit ruang untuk pengguna sepeda.

Hasil skor pada masing - masing parameter kemudian dikalikan dengan factor pengali supaya tidak terjadi bias terhadap parameter yang paling berpengaruh. Faktor pengali tersebut diurutkan terhadap parameter yang paling berpengaruh. Hambatan samping sebagai parameter paling berpengaruh terhadap tingkat kenyamanan jalur sepeda diberikan faktor pengali paling tinggi yaitu 4 , kemudian relief dan arus lalulintas diberi faktor pengali 3 karena pengaruh terhadap tingkat kenyamanan pengendara sepeda sama. Vegetasi peneduh diberikan vaktor pengali 2 sedangkan marka jalur sepeda dan posisi jalur diberikan factor pengali masing - masing 1. 
Berdasarkan hasil dari perkalian masing - masing skor pada parameter, kemudian dilakukan proses pembagian kelas untuk tingkat kenyamanan jalur pengendara sepeda. Pembagian kelas tingkat kenyamanan jalur sepeda ditampilkan pada tabel 3.

Tabel 3. Tabel Klasifikasi Tingkat Kenyamanan Jalur Sepeda

\begin{tabular}{|l|c|}
\hline Tingkat Kenyamanan Jalur Sepeda & Rentang Kelas \\
\hline Sangat Tidak Nyaman & $18-22$ \\
\hline Tidak Nyaman & $23-26$ \\
\hline Sedang & $27-30$ \\
\hline Nyaman & $31-33$ \\
\hline Sangat Nyaman & $34-36$ \\
\hline
\end{tabular}

Sumber: Analisis Data 2015

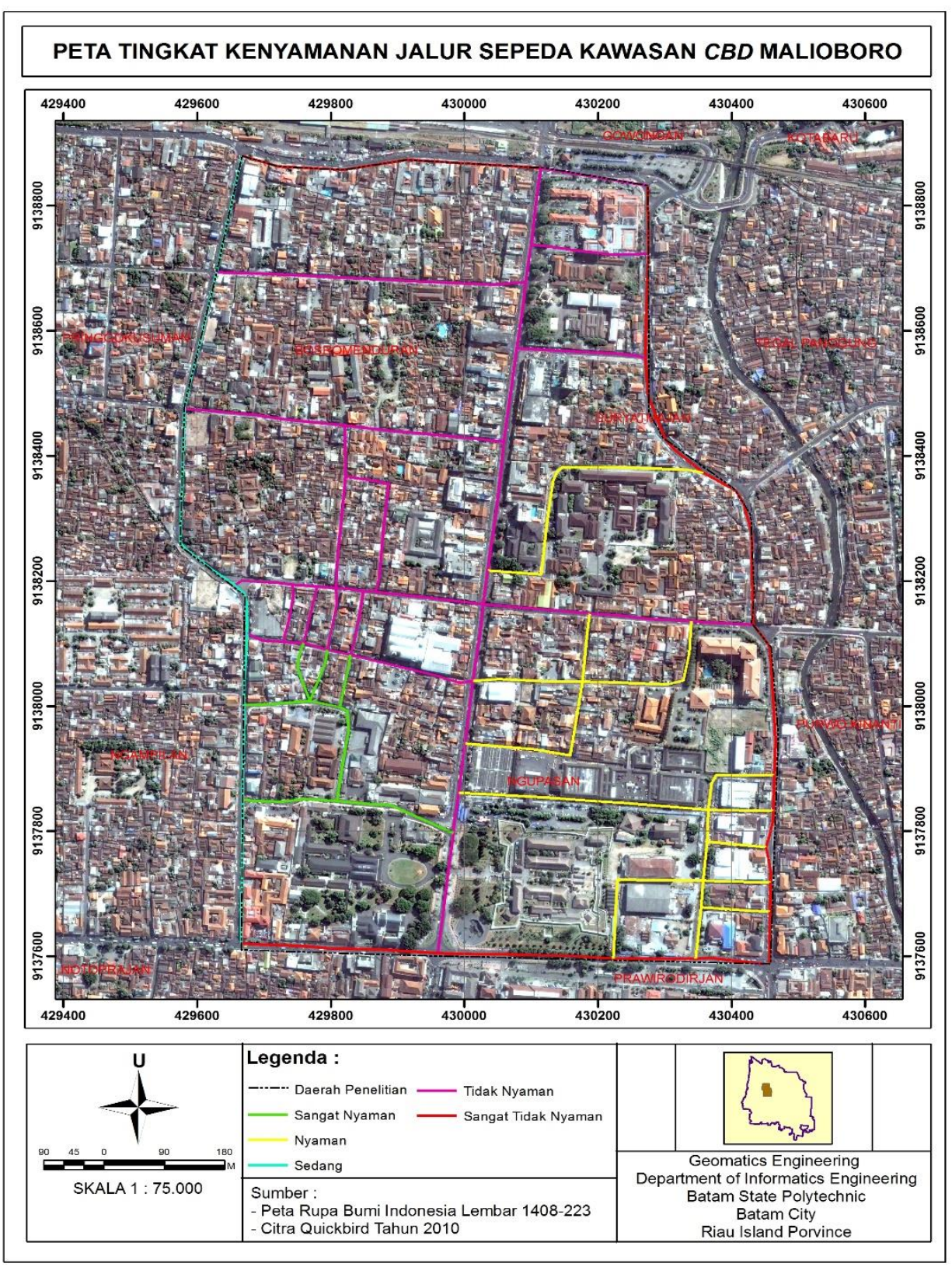

Gambar 4. Peta Tingkat Kenyamanan Jalur Sepeda Kawasan Malioboro 
Hasil Akhir menunjukkan bahwa tingkat kenyamanan jalur sepeda untuk keseluruhan ruas jalan pada kawasan Central Business District (CBD) Malioboro dibagi menjadi 5 kelas tingkat kenyamanan jalur sepeda. 8 jalur sepeda dengan tingkat kelas sangat nyaman, 16 jalur sepeda dengan tingkat kelas nyaman, 7 jalur sepeda dengan tingkat kelas sedang, 38 jalur sepeda dengan tingkat kelas tidak nyaman dan 20 jalur sepeda dengan tingkat kelas sangat tidak nyaman. Sebaran jalur tingkat kenyamanan sepeda daerah kawasan malioboro ini ditampilkan dalam gambar 4.

\section{KESIMPULAN}

Kawasan Malioboro untuk tingkat kenyamanan jalur sepeda hasil ekstraksi data penginderaan jauh menggunakan parameter yang berpengaruh menunjukkan bahwa kawasan tersebut tidak nyaman untuk pengendara sepeda. Hal ini merujuk kepada hasil akhir bahwa untuk kelas jalur sepeda dengan tingkatan tidak nyaman dan sangat tidak nyaman terdapat sebanyak 58 jalur sepeda atau $53 \%$ dari total keseluruhan jalur sepeda yang terdapat di Malioboro.

\section{DAFTAR PUSTAKA}

ANUROGO, W., Murti, S. H., \& Khakhim, N. (2015). ANALISIS PERUBAHAN HUTAN MANGROVE DALAM PENENTUAN KAWASAN REHABILITASI DAN PERUBAHAN STOK KARBON MENGGUNAKAN DATA PENGINDERAAN JAUH (Di Teluk Banten, Serang Provinsi Banten) (Doctoral dissertation, Universitas Gadjah Mada).

Anurogo, W., Lubis, M. Z., Khoirunnisa, H., Hanafi, D. S. P. A., Rizki, F., Surya, G., ... \& Dewanti, N. A. (2017). A Simple Aerial Photogrammetric Mapping
System Overview and Image Acquisition Using Unmanned Aerial Vehicles (UAVs). GEOSPATIAL INFORMATION, 1(1).

Anurogo, W., Lubis, M. Z., Hartono, H., Pamungkas, D. S., \& Dilaga, A. P. Kajian Ketahanan Kawasan Wisata Berbasis Masyarakat Dalam Penguatan Ekonomi Lokal Serta Pelestarian Sumberdaya Kebudayaan Kawasan Kotagede Yogyakarta. Jurnal Ketahanan Nasional, 23(2), 114-136.

Danoedoro, P. (2012). Pengantar Penginderaan Jauh Digital. Yogyakarta: Andi

Farizki, M., \& Anurogo, W. (2017). Pemetaan kualitas permukiman dengan menggunakan penginderaan jauh dan SIG di kecamatan Batam kota, Batam. Majalah Geografi Indonesia, 31(39-45).

HIDAYAT, F. N., \& Widartono, B. S. (2014). PEMODELAN KENYAMANAN JALUR SEPEDA KAMPUS UNIVERSITAS GADJAH MADA MEMANFAATKAN FOTO UDARA FORMAT KECIL (Doctoral dissertation, Universitas Gadjah Mada).

Jensen, J. R. (2009). Remote sensing of the environment: An earth resource perspective 2/e. Pearson Education India

Kiefer, T. M., \& Lillesand, R. W. (1990). Penginderaan Jauh dan Interpretasi Citra. Dulbahri et al, penerjemah. Yogyakarta: Gadjah Mada Unversity Press. Terjemahan dari: Remote Sensing and Image Interpretation.

Lubis, M. Z., Anurogo, W., Oktavianto Gustin, A., Hanafi, A., Timbang, D., Rizki, F., ... \& Taki, H. M. (2017). Interactive modelling of buildings in Google Earth and GIS: A 3D tool for Urban Planning (Tunjuk Island, Indonesia). GEOSPATIAL INFORMATION, 1(2).

Sari, D. P., \& Lubis, M. Z. (2017). Pemanfaatan Citra Landsat 8 Untuk Memetakan Persebaran Lamun Di Wilayah Pesisir Pulau Batam. Jurnal Enggano, 2(1). 